\author{
Marquette University \\ e-Publications@Marquette
}

6-2015

\title{
Cantilever-based Resonant Microsensors with Integrated Temperature Modulation for Transient Chemical Analysis
}

C. Carron

Georgia Institute of Technology - Main Campus

P. Getz

Georgia Institute of Technology - Main Campus

Stephen M. Heinrich

Marquette University, stephen.heinrich@marquette.edu

Fabien Josse

Marquette University, fabien.josse@marquette.edu

Oliver Brand

Georgia Institute of Technology - Main Campus

Follow this and additional works at: https://epublications.marquette.edu/civengin_fac

Part of the Civil and Environmental Engineering Commons

\section{Recommended Citation}

Carron, C.; Getz, P.; Heinrich, Stephen M.; Josse, Fabien; and Brand, Oliver, "Cantilever-based Resonant Microsensors with Integrated Temperature Modulation for Transient Chemical Analysis" (2015). Civil and Environmental Engineering Faculty Research and Publications. 104.

https://epublications.marquette.edu/civengin_fac/104 


\title{
Cantilever-based Resonant Microsensors with Integrated Temperature Modulation for Transient Chemical Analysis
}

\author{
C. Carron \\ School of Electrical \& Computer Engineering, Georgia Institute of \\ Technology \\ Atlanta, Georgia \\ P. Getz \\ School of Electrical \& Computer Engineering, Georgia Institute of \\ Technology \\ Atlanta, Georgia \\ Stephen M. Heinrich \\ Department Civil Engineering, Marquette University \\ Milwaukee, Wisconsin \\ Fabien Josse \\ Department of Electrical and Computer Engineering, Marquette \\ University \\ Milwaukee, Wisconsin \\ Oliver Brand \\ School of Electrical \& Computer Engineering, Georgia Institute of \\ Technology \\ Atlanta, Georgia
}

\begin{abstract}
This work introduces a resonant cantilever platform with integrated temperature modulation for real-time chemical sensing. Embedded heaters allow for rapid thermal cycling of individual sensors, thereby enabling realtime transient signal analysis without the need for a microfluidic setup to switch between analyte and reference gases. Compared to traditional mass-

[2015 ! $8^{\text {th }}$ International Conference on Solid-State Sensors, Actuators, (June 2015): pg. 1511-1514. DOI. This article is C Institute of Electrical and Electronics Engineers (IEEE) and permission has been granted for this version to appear in ePublications@Marquette. Institute of Electrical and Electronics Engineers (IEEE) does not grant permission for this article to be further copied/distributed or hosted elsewhere without the express permission from Institute of Electrical and Electronics Engineers (IEEE).]
\end{abstract}


NOT THE PUBLISHED VERSION; this is the author's final, peer-reviewed manuscript. The published version may be accessed by following the link in the citation at the bottom of the page.

sensitive microsensors operating in steady state, the on-chip generation of signal transients provides additional information for analyte discrimination.

\section{KEYWORDS}

MEMS, chemical sensing, VOC, resonant cantilevers

\section{SECTION I}

\section{INTRODUCTION}

We live in an information-rich era that has come to expect ubiquitous on-demand data delivered at low cost to mobile platforms. This hunger for ever-increasing amounts and types of data has expanded to include chemical and biological information, with the hope that such data hold keys to improving our life. For example, MEMSbased chemical and biological sensors enable more convenient and advanced forms of Point-of-Care Testing (POCT), which can provide patient data in real-time at the patient's bedside. MEMS-based chemical sensors, integrated with mobile platforms, further offer the possibility of distributed realtime environmental monitoring in remote or hazardous locations, where conventional techniques would be impractical or even impossible. By adding additional value in terms of automation and real-time data collection, MEMS-based sensor technologies are even being developed to displace traditional analysis methods for addressing routine pollution concerns (e.g. municipal water supplies and indoor air quality).

Currently, many standard testing systems for chemical analysis consist of bulky desktop equipment (e.g. gas chromatography, mass spectrometry), requiring costly and complex external support systems to process and treat samples with additional reagents and control fluids. Such systems are often expensive and difficult to transport, requiring them to be located at a fixed position in a centrally located facility. Thus, many such standard tests require samples to be transported off-site to a designated testing facility for processing and analysis, which introduces significant time delays and can even lead to inaccuracies in the results due to sample degradation. In instances where the sample analysis leads to a time-sensitive decision (e.g. a clinical decision or a quarantine of a contaminated location), such

[2015 ! $8^{\text {th }}$ International Conference on Solid-State Sensors, Actuators, (June 2015): pg. 1511-1514. DOI. This article is @ Institute of Electrical and Electronics Engineers (IEEE) and permission has been granted for this version to appear in ePublications@Marquette. Institute of Electrical and Electronics Engineers (IEEE) does not grant permission for this article to be further copied/distributed or hosted elsewhere without the express permission from Institute of Electrical and Electronics Engineers (IEEE).] 
delays severely limit the efficacy of the information being gathered. In these cases, the real-time nature of data provided by low-cost MEMSbased sensors can prove more valuable than the superior accuracy of traditional techniques, leading to applications where 'good enough,' in terms of measurement resolution, can be a preferable alternative.

With the goal of developing such real-time mobile sensing platforms, this work demonstrates a resonant cantilever platform with integrated temperature modulation for chemical sensing. The embedded heating elements enable rapid thermal cycling of individual resonant microstructures and, thus, allow for analysis of signal transients, which contain information about the real-time sorption kinetics of analytes into the sensing film on the resonator surface.

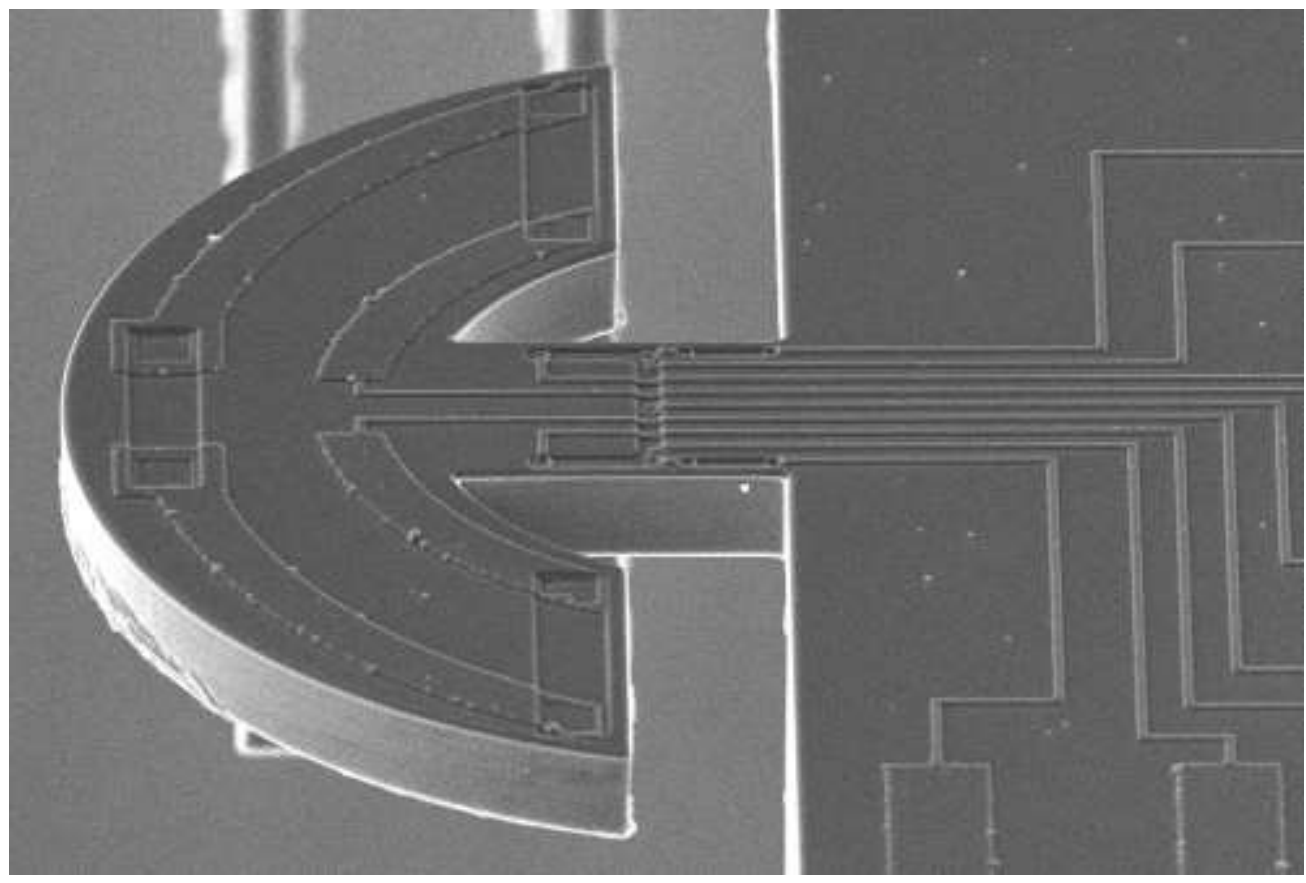

Figure 1: SEM micrograph of resonant microstructure with semicircular head with 200 $\mu \mathrm{m}$ outer radius supported by a $75 \mu \mathrm{m}$ wide and $100 \mu \mathrm{m}$ long cantilever. Resistors for thermal excitation and piezoresistive detection of in-plane flexural vibrations are located at the cantilever base. Three heating resistors for rapid thermal modulation, connected in series, are clearly visible on the semicircular head.

By generating the signal transients through temperature modulation with integrated heating units, this mode of operation

[2015 ! $8^{\text {th }}$ International Conference on Solid-State Sensors, Actuators, (June 2015): pg. 1511-1514. DOI. This article is C Institute of Electrical and Electronics Engineers (IEEE) and permission has been granted for this version to appear in ePublications@Marquette. Institute of Electrical and Electronics Engineers (IEEE) does not grant permission for this article to be further copied/distributed or hosted elsewhere without the express permission from Institute of Electrical and Electronics Engineers (IEEE).] 
eliminates the need for an external microfluidic setup to switch between analyte and reference gas streams. Additionally, the rapid temperature modulation potentially enables intrinsic drift compensation without the need for a reference resonator and generates measurement data in real-time. Combining these two advantages - no need for an external flow system or a reference resonator - can dramatically reduce the complexity and cost of the total system, leading to increased deployability in the field as part of low-power mobile platforms. Finally, when compared to traditional mass-sensitive micro sensors operating in steady state, the on-chip generation of signal transients provides additional information for analyte discrimination and quantification, which can lead to improved sensing performance in the presence of interfering compounds.

\section{SECTION II}

\section{DESIGN \& FABRICATION}

Figure 1 shows an SEM micrograph of a fabricated microresonator consisting of a semicircular head region with inner and outer diameters of $100 \mu \mathrm{m}$ and $200 \mu \mathrm{m}$, respectively, supported by a $75 \mu \mathrm{m}$ wide and $100 \mu \mathrm{m}$ long cantilever beam. Three integrated heating resistors, connected in series, are defined around the perimeter of the semicircular head region and were formed via hightemperature boron diffusion through an oxide mask. As the thermal excitation resistors as well as the piezoresistive sensing resistors connected in a Wheatstone bridge are formed in like manner, the integration of the embedded heating resistors does not require any additional process steps. The total series resistance of the embedded heating unit was designed to have a value of approximately $1 \mathrm{k} \Omega$, allowing for significant temperature elevation with modest applied heating current in the low milliamp range. The overall resonator structure was further designed to allow for rapid and uniform heating of the head area with a minimal thermal time constant.

The fabrication approach for this device represents a slight departure from our previous work -in that the sensing platform is formed on silicon-on-insulator (SOI) substrates and does not utilize

[2015 ! $8^{\text {th }}$ International Conference on Solid-State Sensors, Actuators, (June 2015): pg. 1511-1514. DOI. This article is () Institute of Electrical and Electronics Engineers (IEEE) and permission has been granted for this version to appear in ePublications@Marquette. Institute of Electrical and Electronics Engineers (IEEE) does not grant permission for this article to be further copied/distributed or hosted elsewhere without the express permission from Institute of Electrical and Electronics Engineers (IEEE).] 
$\mathrm{KOH}$ etching to release the finished devices. Instead, a high-aspectratio deep reactive ion etching (DRIE) process is implemented on the reverse-side of the wafer, with the buried oxide (BOX) layer serving as the etch stop. The micromachining used to pattern the top-side of the wafer is similar to our previous designs, with the exception that the DRIE used to pattern the resonator geometry from the top side does not accomplish a final release of the devices but, as with the reverseside DRIE, stops at the BOX layer. Final release is performed by removing the exposed $\mathrm{BOX}$ layer regions with a standard plasma etch for $\mathrm{SiO}_{2}$. While this process arrangement introduces additional complexity into the fabrication of the resonant devices when compared to our previous work, it also offers the ability to define high-aspectratio features onto the reverse-side of the die, making possible novel future designs.

Device operation remains similar to our previous work. The resonator is driven at its fundamental in-plane resonance mode using the aforementioned diffused silicon excitation resistors at the base of the cantilever beam. Four piezoresistors arranged in a U-shaped Wheatstone bridge configuration generate a sensing signal at the desired in-plane mode and enable closed-loop operation of the resonator at its in-plane resonance frequency of approximately 780 kHz. Typical Q-factors for these devices are approximately 2000 in air.

\section{SECTION III}

\section{SIMULATION \& CHARACTERIZATION}

Prior to fabrication, the device performance was simulated and the device geometry was optimized via Finite Element Analysis (FEA). For a $25 \mu \mathrm{m}$ thick resonator, finite element simulations indicate a maximum temperature elevation of $71^{\circ} \mathrm{C}$ at $100 \mathrm{~mW}$ of applied heating power and a uniform temperature profile across the heated head area of the cantilever. This simulated result compares well with experiment: for an applied heating power of $100 \mathrm{~mW}$, the observed temperature increase of the device was $\sim 85^{\circ} \mathrm{C}$ in air. The average temperature increase of the head area was obtained by measuring the heater resistance as a function of the applied heating power and

[2015 ! $8^{\text {th }}$ International Conference on Solid-State Sensors, Actuators, (June 2015): pg. 1511-1514. DOI. This article is @) Institute of Electrical and Electronics Engineers (IEEE) and permission has been granted for this version to appear in ePublications@Marquette. Institute of Electrical and Electronics Engineers (IEEE) does not grant permission for this article to be further copied/distributed or hosted elsewhere without the express permission from Institute of Electrical and Electronics Engineers (IEEE).] 
NOT THE PUBLISHED VERSION; this is the author's final, peer-reviewed manuscript. The published version may be accessed by following the link in the citation at the bottom of the page.

calibrating the temperature-dependence of the heating resistor using a temperature chamber.
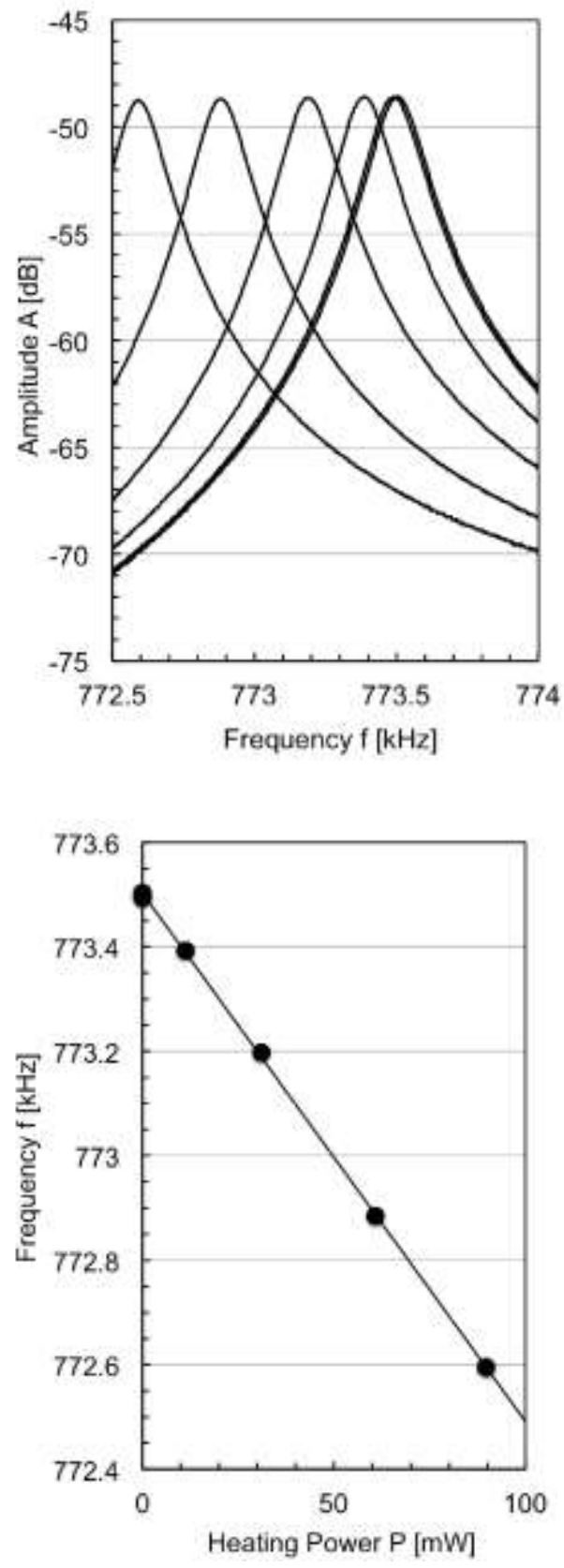

Figure 2: (Left) Amplitude transfer characteristic of in-plane resonant mode as a function of the applied heating power. (Right) Resonant frequency as a function of the applied heating power with a slope of $-10 . \mathrm{IHz} / \mathrm{mW}$ or $-13 \mathrm{ppm} / \mathrm{mW}$

[2015 ! $8^{\text {th }}$ International Conference on Solid-State Sensors, Actuators, (June 2015): pg. 1511-1514. DOI. This article is @ Institute of Electrical and Electronics Engineers (IEEE) and permission has been granted for this version to appear in ePublications@Marquette. Institute of Electrical and Electronics Engineers (IEEE) does not grant permission for this article to be further copied/distributed or hosted elsewhere without the express permission from Institute of Electrical and Electronics Engineers (IEEE).] 
The discrepancy between the simulated and observed temperature elevations is approximately $15 \%$ and can be explained by taking into account differences between the simulated model and the physical device (e.g. thickness variations). Figure 2 shows the openloop amplitude transfer characteristic of the fundamental in-plane mode as a function of the applied heating voltage. The resulting frequency drop is linear with the heating power with a slope of -10.1 $\mathrm{Hz} / \mathrm{mW}$, or $-13 \mathrm{ppm} / \mathrm{mW}$.

The thermal time constant of the heated resonator can also be estimated using finite element modeling and was found to be approximately $1.2 \mathrm{~ms}$ for a $25 \mu \mathrm{m}$-thick resonator. By applying a square-wave heating pulse with a frequency of $100 \mathrm{~Hz}$ to the three series-connected heating resistors and measuring the temperaturedependent resistance change across the Wheatstone bridge, a thermal time constant of $1.1 \mathrm{~ms}$ was experimentally observed, confirming the simulated results. It is important to note that this thermal time constant is 2-3 orders of magnitude shorter than typical analyte diffusion times into polymeric sensing films with micrometer thicknesses. As a result, the resonators can be quickly heated to desorb the analyte out of the polymer film and then rapidly cooled to monitor the analyte absorption back into the polymer in real time. As a result of the rapid cooling of the device, the resonator quickly returns to its original temperature (i.e. the baseline temperature of the device, prior to generating the self-heating transient) and analyte absorption into the polymer sorbent film takes place essentially at room temperature. Because the analyte sorption is recorded at the original operating temperature, the unavoidable frequency shift associated with heating the resonator does not affect the measurement.

\section{SECTION IV}

\section{CHEMICAL MEASUREMENTS}

Following fabrication, and subsequent electrical and thermal characterization, several microresonators were coated with sorbent polymer layers and evaluated for performance as gas-phase chemical sensors. Publications@Marquette. Institute of Electrical and Electronics Engineers (IEEE) does not grant permission for this article to be further copied/distributed or hosted elsewhere without the express permission from Institute of Electrical and Electronics Engineers (IEEE).] 
NOT THE PUBLISHED VERSION; this is the author's final, peer-reviewed manuscript. The published version may be accessed by following the link in the citation at the bottom of the page.

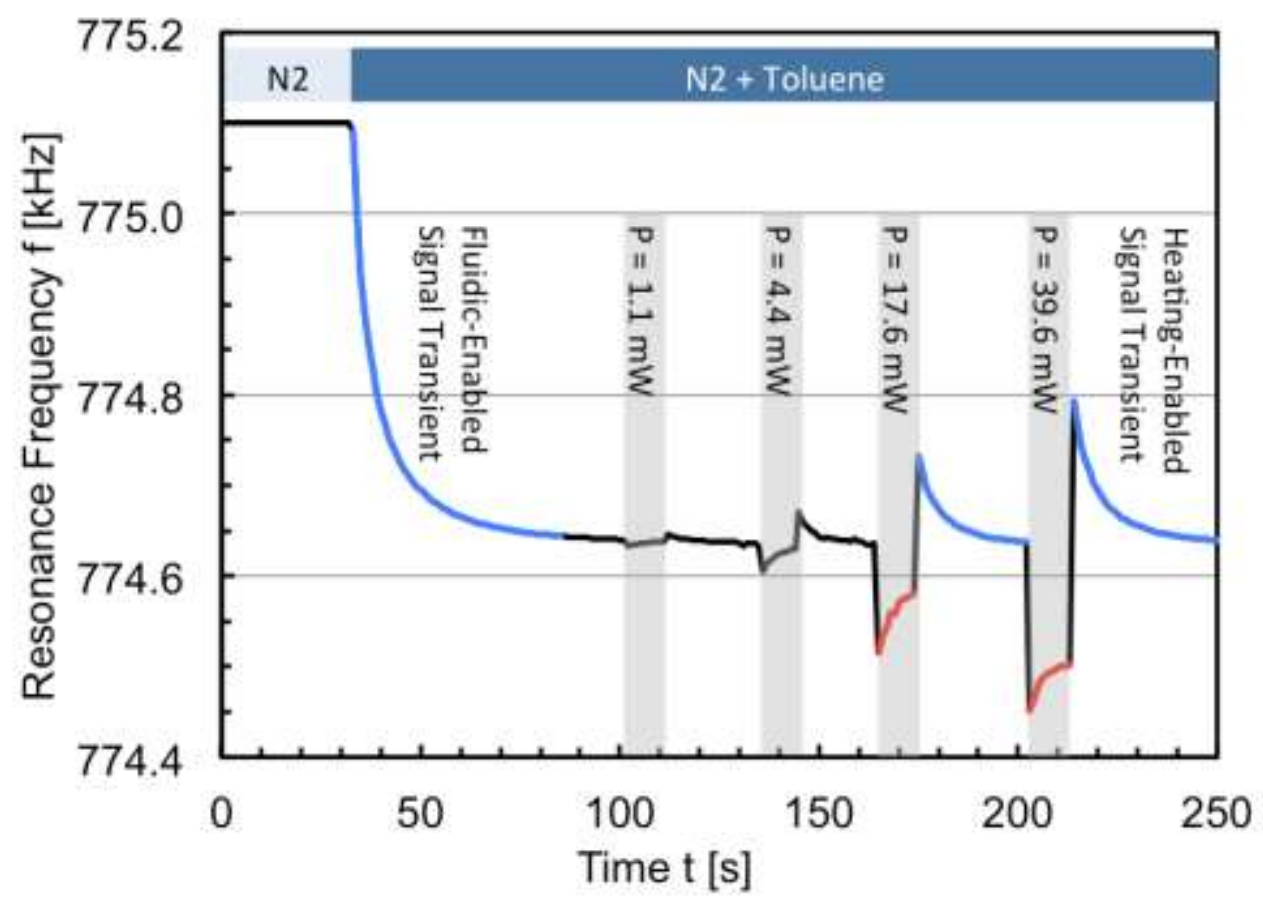

Figure 3: In-plane resonance frequency of $25 \mu \mathrm{m}$ thick microstructure subject to various levels of applied heating power; the PIB-coated resonator is exposed initially to pure carrier gas $\left(\mathrm{N}_{2}\right)$ and then to a constant toluene concentration of 6800ppm; Blue lines represent analyte absorption phases, red lines analyte desorption phases.

Figure 3 summarizes a typical chemical measurement performed with a $25 \mu \mathrm{m}$ thick heated resonator coated with a $2 \mu \mathrm{m}$ thick polyisobutylene (PIB) sorbent polymer layer. After exposing the microstructure to pure carrier gas $\left(\mathrm{N}_{2}\right)$, it was subjected to a continuous flow $(80 \mathrm{ml} / \mathrm{min})$ of toluene at a concentration of 6800 $\mathrm{ppm}$, at a constant temperature of $20^{\circ} \mathrm{C}$. The resulting initial frequency drop of $\sim 1.2 \mathrm{kHz}$ is due to absorption of toluene into the PIB sensing film. While exposing the sensor to a constant toluene concentration, heating pulses of varying power were applied to the three series-connected resistors located on the head region of the resonator, and the resonance frequency of the device was continuously monitored and recorded. As can be seen in Figure 3, the resonance frequency drops quickly when heating power is initially applied due to a rapid increase in the device temperature, which reduces the stiffness of the cantilever beam (due to the temperature dependence of the Young's modulus). Almost immediately after the heating pulse is

[2015 ! $8^{\text {th }}$ International Conference on Solid-State Sensors, Actuators, (June 2015): pg. 1511-1514. DOI. This article is (c) Institute of Electrical and Electronics Engineers (IEEE) and permission has been granted for this version to appear in ePublications@Marquette. Institute of Electrical and Electronics Engineers (IEEE) does not grant permission for this article to be further copied/distributed or hosted elsewhere without the express permission from Institute of Electrical and Electronics Engineers (IEEE).] 
applied, the frequency slowly begins to increase as analyte desorbs from the heated polymer film. After the heating power is turned off, the frequency rapidly shifts upward due to the temperature decrease as device and polymer return to their initial state (as demonstrated before the thermal time constant is approx. $1.1 \mathrm{~ms}$ ) and then slowly decreases again as analyte is reabsorbed into the polymer layer.

The observed sorption transients (blue sections in Fig. 3) can be analyzed further to improve analyte discrimination, as the associated diffusion coefficients are specific to the particular polymer-analyte pair. By plotting (for the three blue absorption cycles in Fig. 3 ) the ratio of the frequency change to the maximum frequency change versus the square-root of time, the initial slopes of the transients, which are proportional to the square-root of the diffusion coefficient, $D$, are observed to agree within 5\%. Thus, signal transients generated via modulation of the on-chip heating units are nearly indistinguishable from those generated due to sudden changes in analyte concentration (e.g. switching via valve between analyte and pure carrier gas streams). Since the transients are generated in a constantconcentration environment, operation in this mode does not require an external flow system for switching between analyte and reference gas streams, thereby reducing cost and complexity in the total sensing platform.

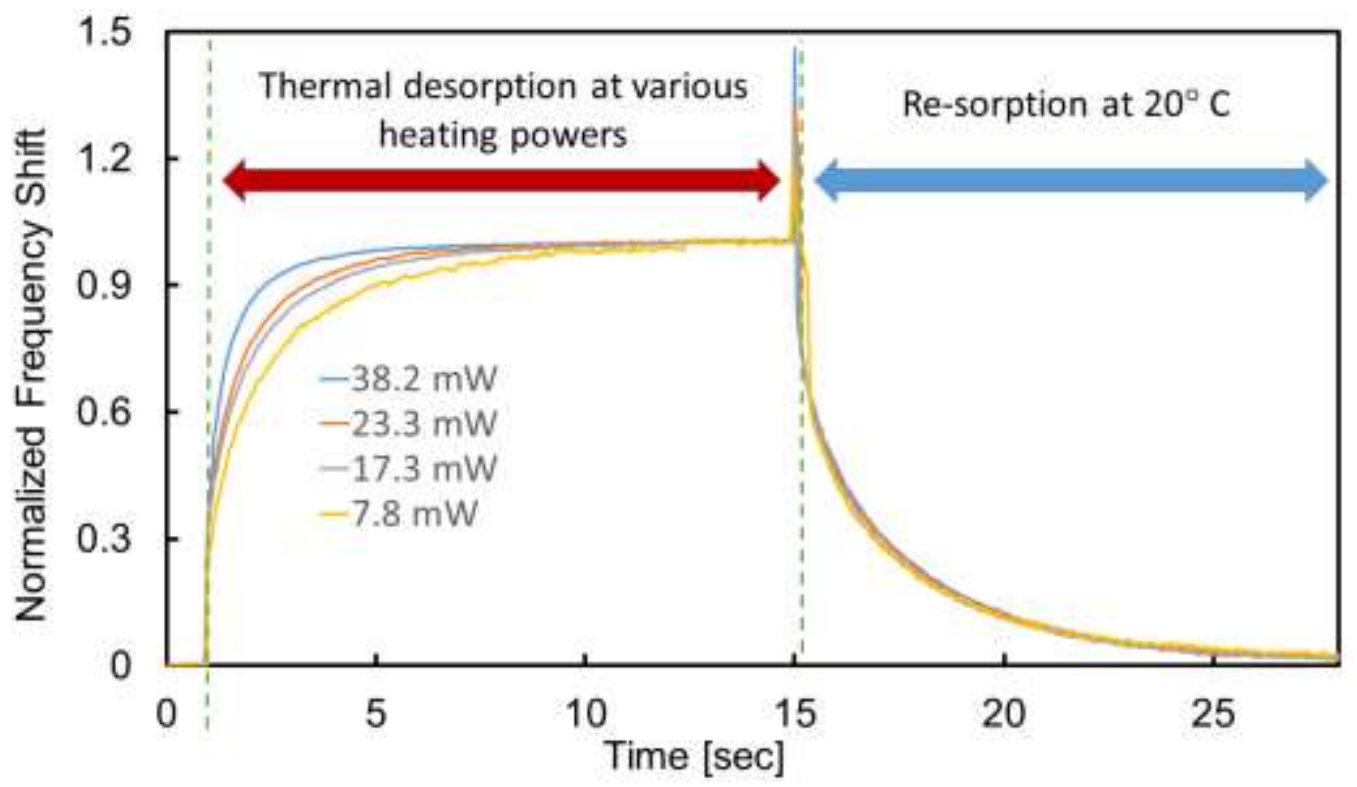

[2015 ! $8^{\text {th }}$ International Conference on Solid-State Sensors, Actuators, (June 2015): pg. 1511-1514. DOI. This article is () Institute of Electrical and Electronics Engineers (IEEE) and permission has been granted for this version to appear in ePublications@Marquette. Institute of Electrical and Electronics Engineers (IEEE) does not grant permission for this article to be further copied/distributed or hosted elsewhere without the express permission from Institute of Electrical and Electronics Engineers (IEEE).] 
NOT THE PUBLISHED VERSION; this is the author's final, peer-reviewed manuscript. The published version may be accessed by following the link in the citation at the bottom of the page.

Figure 4: Series of normalized desorption/absorption transients for increasing heating powers. The resonator was coated with a $2 \mu \mathrm{m}$ thick polyepichlorohydrin (pech) film and exposed to a continuous toluene concentration of $10800 \mathrm{ppm}$. The transients are normalized with respect to their maximum frequency change, and frequency changes caused solely by a temperature change have been removed from these data through a differential measurement.

The temperature-induced analyte desorption can be studied further by separating temperature effects from analyte diffusion effects. To this end, a stair-step pattern of exactly timed heating powers was applied to the resonator first in a pure nitrogen environment and subsequently in a constant atmosphere of toluene. The resulting frequency shifts in the $\mathrm{N}_{2}$-only signal (which represent the sensor's response to temperature alone) were then subtracted from the corresponding shifts in the toluene signal and normalized with respect to maximum frequency shift for a given heating power (Fig. 4). In this way, the temperature response of the sensor stemming from the T-dependence of the Young's modulus can be removed leaving only the response due to analyte sorption. As can be seen in Figure 4, the analyte desorption is temperature-dependent (because the diffusion coefficient depends on temperature), while the normalized rate of re-sorption (which occurs at the same temperature in all cases, because the sensor cools so quickly) is independent of the heating power.

Because of the fast heating, even short heat pulses are sufficient to generate the transients. Figure 5 illustrates a pulsed-mode operation that was performed using a low-power digital-to-analog converter (DAC) and microcontroller to apply precise heating powers to the resonator for $\mathbf{2 0 0} \mathrm{ms}$ durations. As can be seen from the figure, signal transients are generated that require an average total heating power consumption of $900 \mu \mathrm{W}$ per measurement cycle. The generation of low-power transient signals without the use of an external fluidic system introduces novel measurement techniques, and lends itself well to mobile sensing applications.

[2015 ! $8^{\text {th }}$ International Conference on Solid-State Sensors, Actuators, (June 2015): pg. 1511-1514. DOI. This article is C Institute of Electrical and Electronics Engineers (IEEE) and permission has been granted for this version to appear in ePublications@Marquette. Institute of Electrical and Electronics Engineers (IEEE) does not grant permission for this article to be further copied/distributed or hosted elsewhere without the express permission from Institute of Electrical and Electronics Engineers (IEEE).] 
NOT THE PUBLISHED VERSION; this is the author's final, peer-reviewed manuscript. The published version may be accessed by following the link in the citation at the bottom of the page.

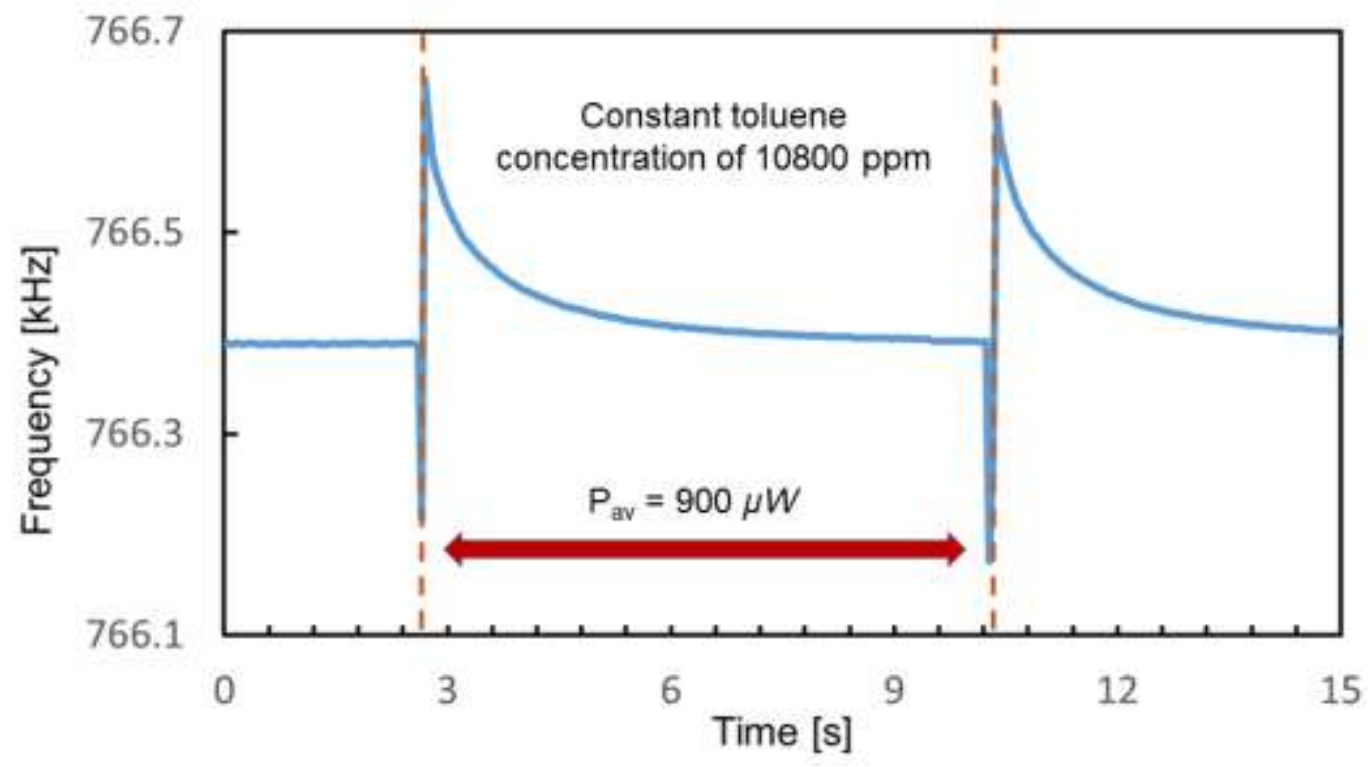

Figure 5: Thermally generated transients based on pulsed-mode operation with 200ms heating pulses, resulting in an average heating power consumption of $900 \mu \mathrm{m}$ per cycle.

\section{SECTION V}

\section{CONCLUSION}

The design, fabrication, and characterization of a novel chemical sensor platform with integrated heating units for the on-chip generation of real-time heating transients is demonstrated. The heater-generated transients are shown to carry nearly identical information as compared to conventionally generated transients (e.g. due to an abrupt change in analyte concentration), enabling a novel mode of sensor operation. This novel operation mode eliminates the need for a reference resonator and external flow system, with a corresponding reduction in total system cost and complexity. Driving down the complexity of chemical sensing systems is essential to improving system deployability in the field and addressing the growing need for real-time information. Furthermore, the thermally generated signal transients provide additional information for analyte

[2015 ! $8^{\text {th }}$ International Conference on Solid-State Sensors, Actuators, (June 2015): pg. 1511-1514. DOI. This article is () Institute of Electrical and Electronics Engineers (IEEE) and permission has been granted for this version to appear in ePublications@Marquette. Institute of Electrical and Electronics Engineers (IEEE) does not grant permission for this article to be further copied/distributed or hosted elsewhere without the express permission from Institute of Electrical and Electronics Engineers (IEEE).] 
discrimination and quantification. Future work will explore improving the Limit of Detection (LOD) of these devices and the possibility of operating arrays of individually-coated sensors with the goal of reducing the platform's sensitivity to chemical interference.

\section{Acknowledgement}

This work was performed in part at Georgia Tech's Institute for Electronics and Nanotechnology, a member of the National Nanotechnology Infrastructure Network (NNIN), which is supported by the National Science Foundation. The authors would like to thank the Institute for Electronics and Nanotechnology (IEN) for help and support with process development and fabrication. The authors would also like to thank the National Science Foundation (NSF) for funding this work through awards ECCS-1128554 and ECCS-1128992.

\section{Reference}

A. Warsinke "Point-of-care testing of proteins" Analytical and Bioanalytical Chemistry, vol. 393, pp. 1393-1405, 2009

C. Ho, A. Robinson, D. Miller and M. Davis "Overview of Sensors and Needs for Environmental Monitoring" Sensors, vol. 5, pp. 437,2005

J. Gooding "Biosensor technology for detecting biological warfare agents: Recent progress and future trends" Analytical Chim. Acta, vol. 559, pp. 137-151, 2006

E. Schleicher "The clinical chemistry laboratory: Current status, problems and diagnostic prospects" Analytical and Bioanalytical Chemistry, vol. 384, pp. 124-131, 2006

A. Kummer, T. Burg and A. Hierlemann "Transient signal analysis using complementary metal oxide semiconductor capacitive chemical microsensors" Analytical Chemistry, vol. 78, pp. 279290, 2006

[2015 ! $8^{\text {th }}$ International Conference on Solid-State Sensors, Actuators, (June 2015): pg. 1511-1514. DOI. This article is (C) Institute of Electrical and Electronics Engineers (IEEE) and permission has been granted for this version to appear in ePublications@Marquette. Institute of Electrical and Electronics Engineers (IEEE) does not grant permission for this article to be further copied/distributed or hosted elsewhere without the express permission from Institute of Electrical and Electronics Engineers (IEEE).] 
NOT THE PUBLISHED VERSION; this is the author's final, peer-reviewed manuscript. The published version may be accessed by following the link in the citation at the bottom of the page.

C. Hagleitner, D. Lange, A. Hierlemann, O. Brand and H. Baltes

"CMOS single-chip gas detection system comprising capacitive, calorimetric and mass-sensitive microsensors" vol. 37, pp. $1867-1878,2002$

D. Lange, C. Hagleitner, A. Hierlemann, O. Brand and H. Baltes "Complementary metal oxide semiconductor cantilever arrays on a single chip: Mass-sensitive detection of volatile organic compounds" Analytical Chemistry, vol. 74, pp. 3084-3095, 2002

P. Xu, H. Yu and X. Li "Functionalized mesoporous silica for microgravimetric sensing of trace chemical vapors" Analytical Chemistry, vol. 83, pp. 3448-3454, 2011

L. Beardslee, K. Demirci, Y. Luzinova, B. Mizaikoff, S. Heinrich, F. Josse and $\mathrm{O}$. Brand "Liquid-phase chemical sensing using lateral mode resonant cantilevers" Journal of Microelectromech. Systems, vol. 19, pp. 1015-1017, 2010

J.-J. Su, C. Carron, S. Truax, K. Demirci, L. Beardslee and O. Brand "Assessing polymer sorption kinetics using micromachined resonators" Transducers 2011, Technical Digest, pp. 14201423,2011

C. Carron, P. Getz, J.-J. Su, D. Gottfried, F. Josse, S. Heinrich and O. Brand "Cantilever-based resonant gas sensors with integrated recesses for localized sensing layer deposition" pp. 1-4

[2015 ! $8^{\text {th }}$ International Conference on Solid-State Sensors, Actuators, (June 2015): pg. 1511-1514. DOI. This article is @ Institute of Electrical and Electronics Engineers (IEEE) and permission has been granted for this version to appear in ePublications@Marquette. Institute of Electrical and Electronics Engineers (IEEE) does not grant permission for this article to be further copied/distributed or hosted elsewhere without the express permission from Institute of Electrical and Electronics Engineers (IEEE).] 